\title{
Maternal mind-mindedness and communicative functions in free-play and mealtime contexts: Stability, continuity and relations with child language at 16 months
}

\author{
Emiddia LONGOBARDI ${ }^{1 \star}$, Pietro SPATARO $^{2}$, and Martina CALABRÒ ${ }^{1}$ \\ ${ }^{1}$ Department of Dynamic and Clinical Psychology, Sapienza University of Rome, Italy and ${ }^{2}$ Department of \\ Economy, Universitas Mercatorum, Rome, Italy \\ *Address for correspondence: Prof. Emiddia Longobardi Department of Dynamic and Clinical Psychology, \\ Sapienza University of Rome, Via degli Apuli 1, 00185 Rome (Italy); \\ E-mail: emiddia.longobardi@uniroma1.it
}

(Received 14 May 2020; revised 8 October 2020; accepted 11 December 2020;

first published online 21 June 2021)

\begin{abstract}
The present study aimed at investigating the contextual stability, the contextual continuity and the concurrent associations between maternal measures (general language, communicative functions and mind-mindedness) and child measures (total number of word types and tokens) in two different contexts, free-play and mealtime. To this purpose, the interactions occurring between 25 mothers and their 16-month-old children in each context were video-recorded, transcribed and later coded for the selected measures. Significant contextual stability was observed in the mothers' production of general language measures (total number of utterances, total number of words and MLU), in the children's production of word types and tokens, and in some communicative functions (Tutorial, Control and Asynchronous). No contextual stability was found for the mothers' production of attuned mind-related comments. For continuity, both mothers and children produced more utterances and words in the free-play than in the mealtime context; the production of attuned mind-related comments and the use of the Control function were also more frequent in the free-play context. Lastly, the analysis of the concurrent correlations indicated that, especially in the mealtime context, the number of words produced by children was positively associated with the number of words produced by mothers and by their use of the Tutorial and Didactic functions, but negatively associated with their use of the Control function. The mothers' production of attuned mind-related comments bore no relation with children's expressive language. Similarities and differences with previous findings are discussed.
\end{abstract}

Keywords: contextual stability; continuity; mind-mindedness: communicative functions; free-play vs. mealtime context

(C) The Author(s), 2021. Published by Cambridge University Press. This is an Open Access article, distributed under the terms of the Creative Commons Attribution licence (http://creativecommons.org/licenses/by/4.0/), which permits unrestricted re-use, distribution, and reproduction in any medium, provided the original work is properly cited. 


\section{Introduction}

Parental responsiveness is a broad concept encompassing sensitivity, support, synchrony, emotional availability, prompt and effective comforting when the child is distressed, and helpful, supportive engagement in play and teaching contexts (Miller, Kim, Boldt, Goffin \& Kochanska, 2019). A plethora of studies have now demonstrated that parental responsiveness plays a key role in shaping several aspects of child development, including attachment security (Lucassen, Tharner, Van IJzendoorn, Bakermans-Kranenburg, Volling, Verhulst, Lambregtse-Van den Berg \& Tiemeier, 2011; Miller et al., 2019), mental and academic skills (Bornstein \& Tamis-LeMonda, 1997; Wade, Jenkins, Venkadasalam, Binnoon-Erez \& Ganea, 2018), emotional self-regulatory abilities (Doan, Fuller-Rowell \& Evans, 2012), internalizing and externalizing behaviors (De Winter, Waters, Braet \& Bosmans, 2018), and language development (Tamis-LeMonda, Bornstein \& Baumwell, 2001; Tamis-LeMonda, Kuchirko \& Song, 2014).

A construct that is closely related to responsiveness is mind-mindedness, traditionally defined as a parent's proclivity to "treat her infant as an individual with a mind rather than merely as a creature with needs that must be satisfied" (Meins, Fernyhough, Fradley \& Tuckey, 2001, p. 638; see McMahon \& Bernier, 2017, for a review). In their first studies, Meins and colleagues assessed mind-mindedness by measuring the number of mental attributes produced by mothers when asked to describe their children (Meins, Fernyhough, Russell \& Clark-Carter, 1998). Later studies have however used an observational approach, by asking mothers to interact with their children, typically during a short free-play session. In this case, the measure of interest was the proportion of attuned comments in which mothers referred to their infants' desires, cognitions and emotions (Meins et al., 2001). Available research indicates that maternal mind-mindedness is positively associated with responsiveness (see Zeegers, Colonnesi, Stams \& Meins, 2017, for a review and meta-analysis); furthermore, the proportions of attuned mind-related comments produced by mothers have been found to predict children's later language (Laranjo \& Bernier, 2013; Longobardi, Spataro \& Colonnesi, 2018; Meins \& Fernyhough, 1999), attachment security (Laranjo, Bernier \& Meins, 2008; Meins et al., 2001, Meins, Fernyhough, de Rosnay, Arnott, Leekam \& Turner, 2012; Miller et al., 2019; Zeegers et al., 2017), theory of mind (Kirk et al., 2015; Laranjo, Bernier, Meins \& Carlson, 2014; Lundy, 2013; Meins, Fernyhough, Wainwright, Clark-Carter, Gupta, Fradley \& Tuckey, 2003; Meins, Fernyhough, Arnott, Leekam \& de Rosnay, 2013), emotion regulation (Centifanti, Meins \& Fernyhough, 2016), symbolic play (Giovanelli et al., 2019), and school readiness (Bernier, McMahon \& Perrier, 2017).

A different line of research has focused on the pragmatic properties of maternal interactive style (Paavola-Ruotsalainen, Lehtosaari, Palomäki \& Tervo, 2018; Masur, Flynn \& Eichorst, 2005; see Tamis-LeMonda et al., 2014, for a review). Collectively, these studies have shown that maternal speech can be used to elicit conversations (McDonald \& Pien, 1982), to direct children's actions (Flynn \& Masur, 2007), to maintain infant attention (Landry, Smith \& Swank, 2006), and/or to provide novel information (Bornstein, Tamis-LeMonda, Tal, Ludemann, Toda, Rahn, Pecheux, Azuma \& Vardi, 1992; D’Odorico, Salerni, Cassibba \& Jacob, 1999). Working in this direction, Longobardi (1992, 1995) and Camaioni, Longobardi, Venuti, and Bornstein (1998) developed a coding scheme in which the caregivers' utterances were classified into five exhaustive communicative categories serving different purposes: 
namely, the TuTORIAL function (maternal comments that support the child's attempts to communicate, maintain the focus of attention or repeat, expand, reformulate, or otherwise acknowledge the child's previous verbal or non-verbal expressions), the DiDACTIC function (maternal comments that transmit new information/knowledge to the child, or confirm the knowledge/ability already available to the child), the Conversational function (maternal comments that promote and maintain the communicative exchange with the child), the ConTrol function (maternal comments that re-orient attention or guide/modify the ongoing action of the child), and the AsYNCHRONOUs function (maternal comments that ignore, or are clearly incongruent, with the child's focus of attention/action). Both early (Longobardi, 1992, 1995) and more recent studies (Longobardi et al., 2018; Majorano, Rainieri \& Corsano, 2013) found that children's language ability was positively predicted by the mothers' use of the Tutorial and Didactic functions and negatively predicted by the use of Control and Asynchronous functions.

Based on this body of findings, the present study was aimed at examining the relations between maternal mind-mindedness, communicative functions and children's expressive language at 16 months of age in two different contexts toy-play and mealtime. We chose to investigate different interactive contexts because they are known to contribute important sources of variability to children's language acquisition during daily family activities (Hoff, 2006, 2010). Different contexts provide children with different opportunities for communicative experience and thereby produce significant group and individual differences in the rate and course of language development. Accordingly, our study had several purposes. First, we wanted to determine the contextual stability and continuity of maternal and children's measures. Second, we aimed at investigating the concurrent associations between mothers' and children's measures. In the following paragraphs, we briefly discuss previous findings that are most relevant to these topics and then illustrate our predictions.

\section{Contextual stability of mothers' and children's measures}

The first aim was to determine whether maternal mind-mindedness, communicative functions and children's language were stable across the play and mealtime contexts. According to Bornstein, Putnick and Esposito (2017), the polarity 'stability/ instability' refers to the degree of consistency (or change) in the relative order, standing, or rank of children in a group on a characteristic through time and is conventionally indexed by correlation. A stable characteristic is one that some children exhibit at high levels relative to others in a group at one point in time and again exhibit at relatively high levels at a later point in time, while other children display low levels at both times. Put in other words, children show stability in a given characteristic if their scores at $\mathrm{T} 1$ are significantly and positively correlated with later scores at T2. While temporal stability represents the form of consistency most frequently investigated in the developmental literature, other forms of consistency can be likewise examined and measured. For example, children who produce a high number of words when speaking to their mothers should produce a comparably high number of words when speaking to their fathers-a form of relational stability. Similarly, children who speak a lot in a play context should be similarly talkative in a book reading context - a form of contextual stability. Like temporal stability, the latter two forms of stability are computed by correlating the 
measures obtained in one relation or in one context with the measure obtained in the other relation or in the other context.

Researchers have begun to apply the concepts of temporal, relational and contextual stability to the study of maternal mind-mindedness and communicative functions, but relatively few data are available and the overall picture is incomplete. Furthermore, some authors have used the term "consistency" to refer to correlations between maternal measures across different relationships (llingworth, MacLean \& Wiggs, 2016) or different contexts (Flynn \& Masur, 2007), whereas the term "stability" has been typically used to refer to correlations across different time points. In the present study we will employ the term "stability" in a more uniform way, to highlight the common nature of the underlying construct and the common measurement method (correlational coefficients).

Regarding maternal mind-mindedness, most studies to date have focused on temporal stability (e.g., Giovanelli et al., 2019; Illingworth et al., 2016). Kirk and colleagues (2015), for example, assessed the mind-mindedness of 18 mothers during a free-play session at $10,12,16$ and 20 months of age. Significant correlations between attuned mind-related comments were obtained at 10 and 12 months, at 10 and 20 months, and at 12 and 16 months, suggesting a high degree of temporal stability. Relational stability has been investigated in a study by Illingworth et al. (2016), in which the mind-mindedness of a sample of 32 mothers having two children between 2.5 and 10 years was measured twice (with a lag of about 9 months) in a free-play context. The results showed a robust stability of maternal mind-mindedness across younger and older siblings at both times (i.e., mothers who used more attuned mind-related comments with their younger children do the same with older children). To our knowledge, only one previous study has looked at contextual stability. Helmerhorst, Colonnesi and Fukkink (2019) measured the mind-mindedness of 99 caregivers during free-play and lunch contexts in infant, preschool and mixed-age (until 4 years of age) childcare centers. No significant correlations between the different mind-mindedness categories (desires and preferences, cognitions, emotions, epistemic state, and talking on behalf of the child) were observed in the two contexts, with $r$ s ranging from -0.12 to 0.00 .

Regarding communicative functions, a recent study by Paavola-Ruotsalainen et al. (2018) assessed four categories of maternal speech at 10 months and again at 2 years: responsive utterances (statements describing persons, actions, feelings, or objects), supportive directives (statements aimed to control the child's physical behavior by suggesting, commanding, or encouraging the child), intrusive behavioral directives (statements aimed to direct the child's focus of attention away from the action or object with which the child is currently engaged), and intrusive attentional directives (statements aimed to redirect or lead the child's focus of attention). The results showed significant stability across age for responsive and supportive utterances, but not for intrusive behavioral directives and intrusive attentional directives (see also Flynn \& Masur, 2007). Similar conclusions have been reached by Masur and Turner (2001), who investigated temporal and contextual stability in the interactive behaviors of 10 boys, 10 girls and their mothers during play and bath sessions when children were 10,13, 17 and 21 months of age. The analyses indicated that maternal responsiveness (measured as the mean ratings of sensitivity to child's interests, responsivity to child's behaviors and effectiveness in engaging the child in the play interaction) was temporally and contextually stable, whereas maternal directiveness (defined as "the frequency and intensity in which the parent requests, 
commands, hints, or attempts in other manners to direct the child's immediate behavior") was both temporally and contextually unstable.

Finally, with respect to infant language, the overall findings suggest that children tend to maintain their individual order in vocabulary size across different time points or different contexts (Bornstein et al., 2017). For example, Bornstein, Tamis-LeMonda and Haynes (1999) assessed the productive vocabulary of 30 children and their mothers in two contexts (play and mealtime) at two child ages (13 and 20 months). The results showed that children's vocabulary exhibited robust temporal and contextual stability (see Bornstein, Hahn \& Haynes, 2004, and Longobardi, Spataro, Putnick \& Bornstein, 2016, for similar conclusions).

\section{Contextual continuity of mothers' and children's measures}

The second aim of the present study was to investigate the contextual continuity of mothers' and children's measures. The polarity 'continuity/discontinuity' refers to changes in the group mean level of a characteristic through different time points and is typically investigated by mean difference tests across time (e.g., Student's paired $t$ tests or $F$ tests: Bornstein et al., 2017). A given measure is said to be temporally continuous if its mean scores do not change across different time points; otherwise, if mean scores at $\mathrm{T} 1$ are higher or lower than those at $\mathrm{T} 2$, it is said to be discontinuous (Bornstein et al., 1999). As for the 'stability/instability' continuum, this polarity has been primarily applied to the temporal domain, whereas other forms of continuity/discontinuity have been rarely investigated, including contextual continuity. In the latter case, the question of interest is whether children's or mothers' mean scores in a given context are equal or different from those obtained in a different context.

For mind-mindedness, the study by Helmerhorst et al. (2019) found that the proportions of attuned mind-related comments did not vary between the free-play and mealtime contexts. However, another study by Farkas et al. (2018) examined the proportions of mental state references produced by 91 mothers in two contexts (free-play and storytelling) when their children were 12 and 30 months of age. The results indicated that, at both ages, mothers produced more mental state references during storytelling than during free play.

Regarding communicative functions, Longobardi (1992) analyzed the way in which 16 mothers used the five communicative categories during the interactions with their 16-month children in three different contexts (play with familiar objects, play with novel objects and mealtime). Significant differences were observed in the Tutorial, Didactic and Control functions: mothers used these three functions more frequently in the play contexts than in mealtime.

Lastly, for children's measures, the study by Bornstein et al. (1999) reported that 20-month-old children produced more words at play than during mealtime, but contextual differences were not evident for 13-month-old children.

\section{Relations between mothers' and children's measures}

The third aim was to assess the concurrent relations between maternal measures (mind-mindedness and communicative functions) and children's language. A number of previous studies investigated this question, but the results were quite mixed. Negative findings were initially reported by Meins et al. (2013), who found 
that the number of attuned mind-related comments produced by mothers at 8 months in a free-play context were not associated with children's internal or non-internal language at 26 months. Different conclusions were however obtained by Laranjo and Bernier (2013) and Bernier et al. (2017). Laranjo and Bernier (2013) showed that attuned mind-related comments at 12 months predicted children's expressive language at 26 months, although the relation was specific to maternal comments on child cognitions. Similarly, in the study by Bernier et al. (2017), mothers' attuned comments at 1 year predicted children's later vocabulary at 2 years. Finally, other researchers found that the positive impact of maternal mind-mindedness was limited to the children's production of mental state language (MSL). Mcquaid, Bigelow, McLaughlin and MacLean (2008) had 33 children discussing an emotionally salient event with their mothers (co-construction) and then relaying the event to a stranger. Correlational analyses indicated that maternal mental state comments were positively and significantly associated with children's mental state comments in the co-construction, but not with the total number of comments produced by children. More recently, Longobardi et al. (2018) reported that the proportions of attuned mind-related comments produced by mothers at 16 months predicted children's internal state language at 20 months but had no significant relation to their non-internal state language.

As for the role of communicative functions, available studies support the predictive influence of specific categories of maternal speech. Two early studies by Longobardi (1992, 1995) found that children's vocabulary size at 20 months was positively correlated with maternal use of the Tutorial and Didactic functions at 16 months, but negatively correlated with the use of the Asynchronous function. These correlations were replicated by Longobardi et al. (2018), who showed that the use of the Tutorial function at 16 months predicted children's non-internal state language at 20 months. Likewise, Majorano et al. (2013) reported that mothers' and fathers' tutorial functions at 15 months predicted child language production at 30 months.

\section{The present study}

In summary, the present study examined the stability, continuity and concurrent relations between mothers' measures (the proportions of attuned and non-attuned mind-related comments and the frequency of use of the Tutorial, Didactic, Conversational, Control and Asynchronous functions) and children's measures (the total number of word types and tokens) in two different contexts (free-play and mealtime) at 16 months. In addition to mind-mindedness and communicative functions, we also assessed maternal general language measures (total number of utterances, total number of words and Mean Length Utterances). Our research was motivated by the identification of several gaps in the existing literature. First, as briefly illustrated above, several studies examining mind-mindedness reported significant temporal and relational stability, but only one study examined contextual stability and found null results (Helmerhorst et al., 2019). Since mind-mindedness has been described as a cognitive-behavioural trait (Meins, Fernyhough, Arnott, Turner \& Leekam, 2011), the implication is that mothers should exhibit consistency in their responses to different situations. Otherwise, if mind-mindedness in one context cannot be used to predict mind-mindedness in another context, then it would be probably more appropriate to think to this dimension of maternal behavior as a relational construct - i.e., a construct which shows substantial variability across 
different contexts (Illingworth et al., 2016). Furthermore, Helmerhorst et al. (2019) investigated caregivers' mind-mindedness, whereas we focused on maternal mind-mindedness. Second, virtually no study has examined the contextual stability of the communicative functions illustrated by Longobardi $(1992,1995)$ and Camaioni et al. (1998). Thus, similar to the case of mind-mindedness, we don't know whether these functions can be regarded as stable traits. Third, previous research has assessed either mind-mindedness or communicative functions, but the relative importance of these two sets of maternal measures has been only compared by Longobardi et al. (2018), who found that they were related to different aspects of children's vocabulary (the tutorial function predicted non-internal language, whereas mind-mindedness predicted internal language). However, in that study, children's language was examined at 20 months using a parent-report questionnaire (the Italian version of the Mac Arthur-Bates Communicative Development Inventory) and mind-mindedness was measured in a play context. The current study aimed at extending these results to a different time point (16 months), a different context (mealtime) and a different measurement method (we used observational, rather than parent-report, measures of children's language).

More specifically, the questions of interest were as follows:

1) Did mothers exhibit stability in the production of mind-related comments and in the use of communicative functions across free-play and mealtime contexts? Were children stable in the production of word types and tokens in the free-play and mealtime contexts?

2) Did mothers use the same amount of mind-related comments and communicative functions in free-play and mealtime contexts? Did children produce the same number of words in the free-play and mealtime contexts?

3) Did the mothers' use of mind-related comments and communicative functions in a given context predict the number of words produced by children in the same context?

\section{Method}

\section{Participants}

Twenty-five children and their mothers participated in the study. They were 14 girls and 11 boys (of which 11 first-borns and 14 second-borns) recruited from kindergartens and pediatrician offices in the metropolitan area of Rome (Italy). All the dyads came from monolingual Italian-speaking families with medium and medium-high socioeconomic status, as based on mother's and father's education (high school or university) and occupations (e.g., clerical worker, teacher, businessman/ businesswoman, professional). Mothers' average age was 36.50 years $(S D=2.20$; range: 31-41). All mothers had jobs outside their home, mostly part time (80\%). Nineteen children (76\%) attended a day nursery during the period of observation, whereas the remaining six children were in the care of grandparents or regular baby-sitters during the parents' working hours. All the measures were obtained from a single home visit that included two video-registrations of mother-infant interactions in two different contexts (play with familiar toys and mealtime) and was conducted when children were about 16 months old (range: 15.30-16.10). No child had known or suspected sensory, intellectual, speech deficits, based on parents' reports. 


\section{Procedure}

Mothers were preliminarily asked their consent to participate in the study, described as a survey of early communicative abilities. At 16 months, a research assistant videotaped the mother-infant interactions in two different contexts: a free-play session (during which the mothers were asked to play with their children as they normally did, using familiar toys already available in the home: Camaioni \& Longobardi, 2001; Longobardi, Rossi-Arnaud, Spataro, Putnick \& Bornstein, 2015b; Longobardi et al., 2018) and a mealtime session (Longobardi, 1992). In both contexts, the video-registrations lasted about $15 \mathrm{~min}$; however, because the exact lengths were slightly different from dyad to dyad, we decided to use only the first $10 \mathrm{~min}$ of each session: they were transcribed verbatim and later coded for maternal and child measures. The study was approved by the ethical committee of the Department of Dynamic and Clinical Psychology of Sapienza University and all the procedures conformed to the ethical principles illustrated in the Declaration of Helsinki.

\section{Maternal measures}

\section{General language}

For each mother, we computed the total number of utterances, the total number of words and the mean length of utterances (MLU) produced during the 10-min free-play and mealtime interactions (Bornstein et al., 1999, 2004).

\section{Communicative functions}

To assess communicative functions, we used a coding scheme developed and validated in previous studies (Camaioni et al., 1998; Longobardi, 1992, 1995; Longobardi, Rienzi, Spataro \& Colonnesi, 2015a; Longobardi et al., 2015a; 2018; Majorano et al., 2013). It includes 21 categories, covering a continuum that ranges from highly synchronized and well-adapted maternal utterances to poorly synchronized or non-attuned utterances (see Camaioni et al., 1998, for a more detailed description). More specifically, categories 1-7 define the TutORIAL function (repetitions, expansions, reformulations, paraphrases, references to a shared experience, references to the roles of a social game, encouragements), categories 8-12 define the DiDActic function (descriptions, closed questions, requests for repetition, labelling, corrections), categories 13-16 define the Conversational function (conversational prompts, open questions, empathic comments, self-responses), categories 17-18 define the ConTrol function (action and/or attention directives), and categories 19-21 define the Asynchronous function (overlapping behaviors, changes of topic, ignoring the child initiative). Note that these categories are mutually exclusive, such that each maternal utterance could be assigned to one and only one category. For each communicative function, the raw numbers of utterances attributed to the defining categories were first summed into a single score; the result was later transformed into a percentage, by dividing it by the total number of utterances produced by mothers and multiplying by 100 (Camaioni et al., 1998; Longobardi et al., 2018). This was done to control for differences in maternal verbosity.

\section{Mind-mindedness}

Mind-mindedness was coded according to the guidelines reported in the Meins and Fernyhough (2015) manual. Five categories of maternal utterances were assessed, 
including: a) comments on the child's mental states (e.g., desires, preferences, knowledge, interests); b) comments on the child's mental processes (e.g., recognizing, thinking, remembering, decision making); c) comments on the child's emotions; d) comments on the child's attempts to manipulate other people's beliefs (e.g., teasing, joking); and e) comments in which the mother "put words into her infant's mouth".

Each mind-related comment was then classified as attuned or non-attuned (Meins \& Fernyhough, 2015). Following Meins et al. (2001), a comment was considered to be 'attuned' if at least one of three criteria were met: an independent coder agreed with the mother's reading of his/her child's mind; the comment linked the child's current activity to related past or future events; or the comment suggested how to proceed after a lull in the interaction. In contrast, a comment was considered to be "non-attuned" if: the coder disagreed with the mother's inference about his/her child's mind; the comment referred to past or future events that were unrelated to the child's current activity; the comment drew the child's attention towards an object or an activity for which he/she exhibited no obvious interest; or the referents of the mother's comment were unclear.

As recommended by Meins et al. (2001), the raw numbers of attuned and non-attuned comments in the five categories were first summed into two total scores, that were later transformed into percentages, by dividing them by the total number of utterances produced by mothers and multiplying by 100 (Meins et al., 2012, 2013).

\section{Child measures}

In addition to maternal measures, the transcribed interactions at 16 months were also examined for children's communicative behaviors. As outlined by Thal and Tobias (1992), a verbal signal was considered to be communicative when the child was clearly attempting to direct the mother's attention (or action). For the current purposes, communicative behaviors comprised all the words produced by children, including patterns of sounds consistently used to refer to specific words ("utto" for "brutto"; Iverson, Longobardi \& Caselli, 2003). Both types and tokens were analyzed (Longobardi et al., 2015b, 2018).

\section{Reliability}

For each context, a randomly selected subset (20\%) of transcribed protocols was coded by a second trained rater, blind to the study aims. In the free-play context, Cohen's $\kappa$ were 0.87 for communicative functions and 0.80 for mind-mindedness; the corresponding inter-rater agreement scores in the mealtime context were 0.91 and 0.88 , respectively.

\section{Results}

\section{Preliminary analyses}

Table 1 reports the descriptive statistics for mothers' and children's measures in the two contexts. In agreement with previous studies (Camaioni et al., 1998; Longobardi, 1992, 1995; Longobardi et al., 2015b, 2018), the Conversational and Control functions were frequently used by mothers (with percentages ranging from $26 \%$ to $44 \%$ ), followed by the Tutorial and Didactic functions (with percentages ranging from $13 \%$ to $16 \%$ ); 
Table 1. Descriptive statistics for maternal and children's measures in the free-play and mealtime contexts

\begin{tabular}{|c|c|c|c|c|c|}
\hline & \multicolumn{2}{|c|}{ Free-play } & \multicolumn{2}{|c|}{ Mealtime } & \multirow[b]{2}{*}{ Stability } \\
\hline & M & $S D$ & M & $S D$ & \\
\hline \multicolumn{6}{|l|}{ Maternal measures } \\
\hline GL: Number of utterances & 166.23 & 43.97 & 124.84 & 30.31 & $r=0.52^{\star \star}$ \\
\hline GL: Number of words & 448.50 & 135.57 & 375.26 & 126.62 & $r=0.63^{\star \star}$ \\
\hline GL: MLU & 2.70 & 1.35 & 2.97 & 0.52 & $r=0.54^{\star \star}$ \\
\hline CF: Tutorial function (\%) & 16.98 & 8.93 & 13.99 & 6.45 & $r=0.40^{\star}$ \\
\hline CF: Didactic function (\%) & 15.57 & 8.36 & 14.74 & 7.35 & $r=-0.06$ \\
\hline CF: Conversational function (\%) & 32.72 & 6.89 & 44.81 & 8.72 & $r=0.01$ \\
\hline CF: Control function (\%) & 32.89 & 9.26 & 26.26 & 8.54 & $r=0.39^{\star}$ \\
\hline CF: Asynchronous function (\%) & 1.81 & 3.29 & 0.18 & 0.54 & $r=0.67^{\star \star}$ \\
\hline MM: Attuned comments (\%) & 11.51 & 3.19 & 9.20 & 4.17 & $r=0.08$ \\
\hline MM: Non-attuned comments (\%) & 0.60 & 1.46 & 0.00 & 0.00 & NA \\
\hline \multicolumn{6}{|l|}{ Child measures } \\
\hline Number of words (types) & 57.38 & 24.61 & 13.61 & 14.60 & $r=0.58^{\star \star}$ \\
\hline Number of words (tokens) & 118.61 & 51.94 & 50.23 & 43.34 & $r=0.49 * *$ \\
\hline
\end{tabular}

Note. ${ }^{\star}: p \leqslant 0.05 ;{ }^{\star \star}: p \leqslant 0.01 ; \mathrm{GL}$ : general language; CF: communicative functions; MM: mind-mindedness; NA: not applicable.

as expected, the asynchronous function was rarely used in our sample (less than $2 \%$ ). With respect to mind-mindedness, the mean percentages of attuned mind-related comments in the two contexts (11\% and 9\%) appeared to be higher than those typically reported by Meins and colleagues (e.g., 5.34\%: Meins et al., 2012, 2013), but in line with the estimates computed by Helmerhorst et al. (2019). Non-attuned comments were extremely rare in the free-play context (less than 1.00\%) and were never produced in the mealtime context (see Bernier et al., 2017, and Laranjo \& Bernier, 2013, for similar results).

A preliminary inspection of skewness and kurtosis values was conducted to assess whether maternal and children's measures were normally distributed (note that, since no mother produced non-attuned mind-related comments in the mealtime context, skewness and kurtosis values could not be computed for this measure). For the present purposes, values of skewness and kurtosis between -2 and +2 were considered acceptable in order to prove normal univariate distribution (George \& Mallery, 2010). The Asynchronous function deviated from normality in both the free-play (skewness: 2.22; kurtosis: 4.20) and mealtime (skewness: 2.73; kurtosis: 6.37) contexts. In addition, the percentages of non-attuned mind-related comments deviated from normality in the free-play context (skewness: 2.67; kurtosis: 6.67). These three measures were analyzed with both parametric and non-parametric statistical analyses. Since the results were comparable, only the parametric analyses will be reported below. 


\section{Contextual stability of maternal measures}

Stability of maternal measures across the two contexts was investigated with Pearson's correlations (see Table 1). For each measure, we determined whether scores in the free-play context were significantly associated with scores in the mealtime context. Regarding general language measures, the results indicated that mothers were highly stable in the number of utterances and words produced in the free-play and mealtime contexts $(r=0.52, p=0.007$ and $r=0.63, p=0.001$, respectively), as well as in their MLU $(r=0.54, p=0.004)$. For communicative functions, significant contextual stability was observed for the Tutorial function $(r=0.40, p=0.042)$, for the Control function $(r=0.39, p=0.050)$, and for the Asynchronous function $(r=0.67$, $p<0.001)$. The Didactic and Conversational functions proved to be unstable $(r=-0.06$, $p=0.73$ and $r=0.01, p=0.97$, respectively). Finally, for mind-mindedness there was no evidence of stability in the percentages of attuned mind-related comments produced by mothers across the two contexts $(r=0.08, p=0.72)$. Stability could not be computed for non-attuned comments, because they were never used in the mealtime context.

Following Bornstein et al. (1999), significant correlations were followed-up by a series of hierarchical regressions aimed at determining whether maternal measures exhibited contextual stability when child measures were controlled for by entering them in the first step. These analyses are justified by the well-known finding that mothers tend to modify their speech to correspond to the changing properties of their children's language (i.e., the amount of child-directed speech increases as soon as the child produces more words, especially during the second year of life: Flynn \& Masur, 2007; Pan, Imbens-Bailey, Winner \& Snow, 1996). Since correlations are by definition bidirectional, we performed separate analyses to determine: a) whether maternal measures in the mealtime context predicted maternal measures in the free-play context after controlling for the number of word tokens produced by children in the free-play context (Table 2); and b) whether maternal measures in the free-play context predicted maternal measures in the mealtime context after controlling for the number of word tokens produced by children in the mealtime context (Table 3). For children, we only considered the number of word tokens, because correlations with the number of word types were so high $(r=0.88$ in the free-play context and $r=0.79$ in the mealtime context) that including both measures in the same regression would have resulted in problems of multicollinearity.

Collectively, these two sets of analyses confirmed the stability of mothers' general language measures (number of utterances, number of words and MLU). For communicative functions, a remarkable stability was observed in the Asynchronous function; in contrast, the analyses involving the Tutorial and Control functions fell below the significance level $(p=0.067$ and $p=0.060$ in the analyses predicting maternal measures in the free-play context, and $p=0.31$ and $p=0.091$ in the analyses predicting maternal measures in the mealtime context).

\section{Contextual stability of children's measures}

Contextual stability was also investigated for children's measures: that is, we again asked whether scores in the free-play context correlated with scores in the mealtime context. Replicating previous findings (Bornstein et al., 1999), children were found to be moderately stable in the number of words produced in the two contexts $(r=0.49$, $p=0.011$ for types and $r=0.58, p=0.002$ for tokens; see Table 1 ). 
Table 2. Hierarchical regressions predicting mothers' and children's measures in the free play context from the same measures in the mealtime context.

\begin{tabular}{|c|c|c|c|c|}
\hline \multirow[b]{2}{*}{ Predictors } & \multicolumn{4}{|c|}{$\mathrm{DP}=$ Mother number of utterances (free play) } \\
\hline & $\beta$ & $\mathrm{t}$ & Step F & Step $\mathrm{R}^{2}$ \\
\hline 1. Child word tokens (free play) & 0.06 & 0.32 & $F(1,24)=2.49$ & 0.09 \\
\hline \multirow[t]{2}{*}{ 2. Mother number of utterances (mealtime) } & 0.49 & $2.36^{\star}$ & $F(1,23)=5.61^{\star}$ & 0.18 \\
\hline & \multicolumn{4}{|c|}{$D P=$ Mother number of words (free play) } \\
\hline Predictors & $\beta$ & $t$ & Step $F$ & Step $R^{2}$ \\
\hline 1. Child word tokens (free play) & 0.20 & 1.10 & $F(1,24)=6.67^{*}$ & 0.22 \\
\hline \multirow[t]{2}{*}{ 2. Mother number of words (mealtime) } & 0.53 & $2.88^{\star \star}$ & $F(1,23)=8.29^{\star \star}$ & 0.21 \\
\hline & \multicolumn{4}{|c|}{$D P=$ Mother $M L U$ (free play) } \\
\hline Predictors & $\beta$ & $t$ & Step $F$ & Step $R^{2}$ \\
\hline 1. Child word tokens (free play) & 0.32 & $1.88 \dagger$ & $F(1,24)=6.26^{\star}$ & 0.21 \\
\hline \multirow[t]{2}{*}{ 2. Mother MLU (mealtime) } & 0.44 & $2.59^{\star}$ & $F(1,23)=6.71^{\star}$ & 0.18 \\
\hline & \multicolumn{4}{|c|}{$D P=$ Mother Tutorial function (free play) } \\
\hline Predictors & $\beta$ & $t$ & Step $F$ & Step $R^{2}$ \\
\hline 1. Child word tokens (free play) & 0.38 & $2.12^{\star}$ & $F(1,24)=5.44^{\star}$ & 0.19 \\
\hline \multirow[t]{2}{*}{ 2. Mother Tutorial function (mealtime) } & 0.34 & $1.92 \dagger$ & $F(1,23)=3.71 \dagger$ & 0.11 \\
\hline & \multicolumn{4}{|c|}{$D P=$ Mother Control function (free play) } \\
\hline Predictors & $\beta$ & $t$ & Step $F$ & Step $R^{2}$ \\
\hline 1. Child word tokens (free play) & -0.29 & -1.63 & $F(1,24)=2.95$ & 0.11 \\
\hline \multirow[t]{2}{*}{ 2. Mother Control function (mealtime) } & 0.36 & $1.98 \dagger$ & $F(1,23)=3.92 \dagger$ & 0.13 \\
\hline & \multicolumn{4}{|c|}{$D P=$ Mother Asynchronous function (free play) } \\
\hline Predictors & $\beta$ & $t$ & Step F & Step $R^{2}$ \\
\hline 1. Child word tokens (free play) & -0.16 & -1.06 & $F(1,24)=0.71$ & 0.03 \\
\hline \multirow[t]{2}{*}{ 2. Mother Asynchronous function (mealtime) } & 0.66 & $4.38^{\star \star}$ & $F(1,23)=19.21^{\star \star}$ & 0.44 \\
\hline & \multicolumn{4}{|c|}{$D P=$ Child number of words (types - free play) } \\
\hline Predictors & $\beta$ & $t$ & Step $F$ & Step $R^{2}$ \\
\hline 1. Mother number of words (free play) & 0.45 & $2.77^{\star \star}$ & $F(1,24)=9.73^{\star \star}$ & 0.29 \\
\hline \multirow[t]{2}{*}{ 2. Child number of words (types - mealtime) } & 0.37 & $2.32^{\star}$ & $F(1,23)=5.39^{\star}$ & 0.14 \\
\hline & \multicolumn{4}{|c|}{$D P=$ Child number of words (tokens - free play) } \\
\hline Predictors & $\beta$ & $t$ & Step $F$ & Step $R^{2}$ \\
\hline 1. Mother number of words (free play) & 0.36 & $2.27^{\star}$ & $F(1,24)=6.67^{\star}$ & 0.22 \\
\hline 2. Child number of words (tokens - mealtime) & 0.50 & $3.17^{\star \star}$ & $F(1,23)=10.11^{\star *}$ & 0.24 \\
\hline
\end{tabular}

Note. †: $0.05<p<0.10 ;{ }^{*}: p \leqslant 0.05 ;{ }^{\star \star}: p \leqslant 0.01$; DP: dependent variable. 
Table 3. Hierarchical regressions predicting mothers' and children's measures in the mealtime context from the same measures in the free play context.

\begin{tabular}{|c|c|c|c|c|}
\hline \multirow[b]{2}{*}{ Predictors } & \multicolumn{4}{|c|}{$D P=$ Mother number of utterances (mealtime) } \\
\hline & $\beta$ & $t$ & Step F & Step $R^{2}$ \\
\hline 1. Child word tokens (mealtime) & 0.44 & $2.88^{* *}$ & $F(1,24)=5.69^{\star}$ & 0.19 \\
\hline \multirow[t]{2}{*}{ 2. Mother number of utterances (free play) } & 0.52 & $3.40^{\star \star}$ & $F(1,23)=11.60^{\star *}$ & 0.27 \\
\hline & \multicolumn{4}{|c|}{$D P=$ Mother number of words (mealtime) } \\
\hline Predictors & $\beta$ & $t$ & Step F & Step $R^{2}$ \\
\hline 1. Child word tokens (mealtime) & 0.20 & 1.25 & $F(1,24)=2.88$ & 0.11 \\
\hline \multirow[t]{2}{*}{ 2. Mother number of words (free play) } & 0.58 & $3.63^{* *}$ & $F(1,23)=13.19^{\star \star}$ & 0.33 \\
\hline & \multicolumn{4}{|c|}{$D P=$ Mother MLU (mealtime) } \\
\hline Predictors & $\beta$ & $t$ & Step F & Step $R^{2}$ \\
\hline 1. Child word tokens (mealtime) & -0.33 & -1.71 & $F(1,24)=0.05$ & 0.00 \\
\hline \multirow[t]{2}{*}{ 2. Mother MLU (free play) } & 0.72 & $3.67^{\star \star}$ & $F(1,23)=13.51^{\star \star}$ & 0.37 \\
\hline & \multicolumn{4}{|c|}{$D P=$ Mother Tutorial function (mealtime) } \\
\hline Predictors & $\beta$ & $t$ & Step $F$ & Step $R^{2}$ \\
\hline 1. Child word tokens (mealtime) & 0.41 & $2.07^{\star}$ & $F(1,24)=8.46^{\star \star}$ & 0.26 \\
\hline \multirow[t]{2}{*}{ 2. Mother Tutorial function (free play) } & 0.21 & 1.03 & $F(1,23)=1.06$ & 0.03 \\
\hline & \multicolumn{4}{|c|}{$D P=$ Mother Control function (mealtime) } \\
\hline Predictors & $\beta$ & $t$ & Step $F$ & Step $R^{2}$ \\
\hline 1. Child word tokens (mealtime) & -0.42 & $-2.42^{*}$ & $F(1,24)=7.24^{\star \star}$ & 0.23 \\
\hline \multirow[t]{2}{*}{ 2. Mother Control function (free play) } & 0.31 & $1.76 \dagger$ & $F(1,23)=3.10 \dagger$ & 0.09 \\
\hline & \multicolumn{4}{|c|}{$D P=$ Mother Asynchronous function (mealtime) } \\
\hline Predictors & $\beta$ & $t$ & Step $F$ & Step $R^{2}$ \\
\hline 1. Child word tokens (mealtime) & 0.01 & 0.05 & $F(1,24)=0.99$ & 0.04 \\
\hline \multirow[t]{2}{*}{ 2. Mother Asynchronous function (free play) } & 0.67 & $4.09^{* *}$ & $F(1,23)=16.80^{\star \star}$ & 0.41 \\
\hline & \multicolumn{4}{|c|}{$D P=$ Child number of words (types - mealtime) } \\
\hline Predictors & $\beta$ & $t$ & Step F & Step $R^{2}$ \\
\hline 1. Mother number of words (mealtime) & 0.17 & 0.87 & $F(1,24)=3.36 \dagger$ & 0.12 \\
\hline \multirow[t]{2}{*}{ 2. Child number of words (types - free play) } & 0.40 & $2.02^{*}$ & $F(1,23)=4.08^{\star}$ & 0.13 \\
\hline & \multicolumn{4}{|c|}{$D P=$ Child number of words (tokens - mealtime) } \\
\hline Predictors & $\beta$ & $t$ & Step $F$ & Step $R^{2}$ \\
\hline 1. Mother number of words (mealtime) & 0.05 & 0.25 & $F(1,24)=2.88$ & 0.11 \\
\hline 2. Child number of words (tokens - free play) & 0.55 & $2.81^{\star \star}$ & $F(1,23)=7.93^{\star \star}$ & 0.23 \\
\hline
\end{tabular}

Note. $\dagger: 0.05<p<0.10 ;{ }^{\star}: p \leqslant 0.05 ;{ }^{\star \star}: p \leqslant 0.01$; DP: dependent variable. 
As for maternal measures, significant correlations were followed-up by two hierarchical regressions aimed at determining whether children's measures exhibited contextual stability when maternal measures were controlled for by entering them in the first step. More specifically, we wanted to determine: a) whether the number of words produced by children in the mealtime context predicted the number of words produced by the same children in the free-play context after controlling for the number of words produced by mothers in the free-play context (Table 2); and b) whether the number of words produced by children in the free-play context predicted the number of words produced by the same children in the mealtime context after controlling for the number of words produced by mothers in the mealtime context (Table 3). The results of these analyses confirmed the stability of children's measures in both cases.

\section{Contextual continuity of maternal measures}

Continuity of maternal measures between the two contexts was investigated through paired-sample $t$-tests. That is, for each measure, we asked whether mean scores in the free-play context were equal or different from mean scores in the mealtime context. For general language measures, the analyses indicated that mothers produced more utterances and more words in the free-play than in the mealtime context $[t(25)=5.50, p<0.001$ and $t(25)=13.71, p<0.001$, respectively]. In contrast, MLU was higher in the mealtime than in the free-play context $[t(25)=-3.05, p=0.005$; see Table 1 for the means]. For communicative functions (see Figure 1), significant differences were observed in the Conversational $[t(25)=-5.56, p<0.001]$, Control $[t(25)=3.43, p=0.002]$ and Asynchronous $[t(25)=2.80, p=0.010]$ functions. Mothers used the Control and Asynchronous functions more frequently in the free-play than in the mealtime context; on the other hand, the Conversational function was used more often in the mealtime than in the free-play context. The use of the Tutorial function was also more frequent in the free-play than in the mealtime context, but the difference failed to reach the significance level $[t(25)=1.75, p=0.091]$. Lastly, for mind-mindedness significant differences were obtained in the percentages of attuned mind-related comments $[t(25)=2.32, p=0.028]$ : they occurred more frequently in the play than in the mealtime context (see Figure 1). The percentages of nonattuned comments were also numerically higher in the play than in the mealtime context: however, these differences were not statistically analyzed, because mothers did not produce this type of comments in the mealtime context.

\section{Contextual continuity of children's measures}

In line with Bornstein et al. (1999), paired-sample $t$-tests indicated that children produced more words in the free-play than in the mealtime context $[t(25)=10.24$, $p<0.001$ for types and $t(25)=7.85, p<0.001$ for tokens].

\section{Concurrent relations between maternal and children's measures}

Table 4 illustrates the concurrent correlations between mothers' and children's measures in each context. Pearson correlations were used in all cases.

In the free-play context, the total number of words produced by mothers and their MLU were positively and significantly associated with the total number of words 


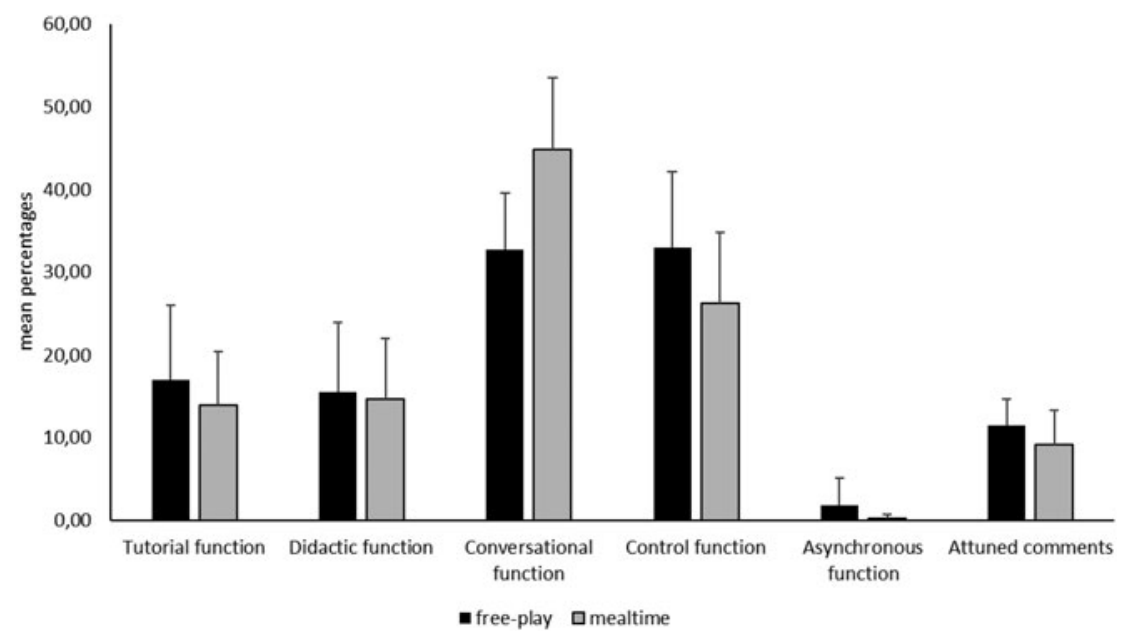

Figure 1. Mean percentages for communicative functions (tutorial, didactic, conversational, control and asynchronous) and mind-mindedness (attuned comments) in the free-play and mealtime contexts. Bars represent standard deviations.

Table 4. Concurrent correlations between maternal and children's measures in the free-play and mealtime contexts

\begin{tabular}{|c|c|c|c|c|}
\hline \multirow[b]{2}{*}{ Children's number of words } & \multicolumn{2}{|c|}{ Free-play } & \multicolumn{2}{|c|}{ Mealtime } \\
\hline & Types & Tokens & Types & Tokens \\
\hline \multicolumn{5}{|l|}{ Mother measures } \\
\hline GL: Number of utterances & $0.38 \dagger$ & 0.30 & $0.37 \dagger$ & $0.43^{*}$ \\
\hline GL: Number of words & $0.53^{\star \star}$ & $0.46^{\star}$ & $0.35 \dagger$ & 0.32 \\
\hline GL: MLU & $0.48^{\star \star}$ & $0.45^{\star}$ & 0.16 & 0.04 \\
\hline CF: Tutorial function (\%) & $0.37 \dagger$ & $0.43^{*}$ & $0.59^{\star \star}$ & $0.51^{\star *}$ \\
\hline CF: Didactic function (\%) & -0.03 & -0.08 & $0.33 \dagger$ & $0.50^{\star *}$ \\
\hline CF: Conversational function (\%) & 0.05 & 0.06 & -0.21 & -0.32 \\
\hline CF: Control function (\%) & $-0.39^{\star}$ & $-0.33 \dagger$ & $-0.51^{\star *}$ & $-0.48^{\star *}$ \\
\hline CF: Asynchronous function (\%) & 0.06 & -0.17 & -0.16 & -0.20 \\
\hline MM: Attuned comments (\%) & 0.00 & 0.08 & -0.29 & -0.23 \\
\hline MM: Non-attuned comments (\%) & 0.07 & 0.00 & NA & NA \\
\hline
\end{tabular}

Note. $\dagger: 0.05<p<0.10 ;{ }^{*}: p \leqslant 0.05 ;{ }^{* *}: p \leqslant 0.01 ; \mathrm{GL}$ : general language; CF: communicative functions; MM: mind-mindedness; NA: not applicable.

produced by children ( $p=0.005$ and $p=0.012$ for types, and $p=0.016$ and $p=0.020$ for tokens). For communicative functions, the use of the Tutorial function was positively correlated with children's production of word tokens $(p=0.028)$, whereas the use of the Control function was negatively correlated with children's production of word types $(p=0.048)$. The positive correlations between the total number of utterances 
produced by mothers and children's production of word types $(p=0.055)$ and between the mothers' use of the Tutorial function and children's production of word types $(p=$ 0.060) showed marginal tendencies towards the significance level, as did the negative correlation between the mothers' use of the Control function and the children's production of word tokens $(p=0.099)$. Finally, the correlations between the proportions of attuned and non-attuned mind-related comments produced by mothers and children's production of word types and tokens were all close to zero.

In the mealtime context, the total number of utterances produced by mothers was positively and significantly associated with the total number of word tokens produced by children $(p=0.025)$. For communicative functions, the correlations between the mothers' use of the Tutorial function and the total number of word types and tokens produced by children were positive and significant $(p=0.001$ and $p=0.008$, respectively), as was the correlation between the mothers' use of the Didactic function and the total number of word tokens produced by children $(p=0.009)$. In contrast, the mothers' use of the Control function was negatively correlated with children's production of word types and tokens $(p=0.007$ and $p=0.013$, respectively). The positive correlations between the total number of utterances and words produced by mothers and the children's production of word types $(p=0.061$ and $p=0.079$, respectively), and between the mothers' use of the Didactic function and the total number of word types produced by children ( $p=0.090)$, showed marginal tendencies towards the significance level. Lastly, the correlations between the proportions of attuned mind-related comments produced by mothers and children's production of word types and tokens were not significant.

Significant correlations were followed up by a series of hierarchical regressions aimed at determining whether maternal communicative functions predicted the number of words produced by children in each context after controlling for the total number of utterances produced by mothers in the same context (this was done to minimize interdependence of speech category: Flynn \& Masur, 2007). Since children's productivity was measured in two different ways, we performed separate analyses for word types (see Table 5) and tokens (see Table 6). For types, the results showed that the children's production of words in the mealtime context was positively predicted by the mothers' use of the tutorial function in the same context and negatively predicted by the use of the control function. Similarly, for tokens, the results showed that the children's production of words in the mealtime context was significantly and positively predicted by the mothers' use of the tutorial and didactic functions in the same context, but negatively predicted by the use of control function. In addition, children's production of words in the free play context was marginally predicted by the mothers' use of the tutorial function.

\section{Discussion}

The present study examined child-mother interactions at 16 months in two different contexts, free-play and mealtime. Our primary aims were a) to assess the contextual stability and continuity of maternal measures (general language, communicative functions and mind-mindedness) and child measures (total number of word types and tokens); and b) to evaluate the concurrent relations between mothers' and children's language. The results advance our knowledge in several ways. First, no previous study has assessed the contextual stability and continuity of maternal mind-mindedness at 16 months. To recap, we found that maternal mind-mindedness 
Table 5. Hierarchical regressions predicting children's number of word types from maternal measures

\begin{tabular}{|c|c|c|c|c|}
\hline \multirow[b]{2}{*}{ Predictors } & \multicolumn{4}{|c|}{$D P=$ Child number of word types (free play) } \\
\hline & $\beta$ & $t$ & Step $F$ & Step $R^{2}$ \\
\hline 1. Mother number of utterances (free play) & 0.30 & 1.59 & $F(1,24)=4.07 \dagger$ & 0.15 \\
\hline \multirow[t]{2}{*}{ 2. Mother Tutorial function (free play) } & 0.29 & 1.54 & $F(1,23)=2.39$ & 0.08 \\
\hline & \multicolumn{4}{|c|}{$D P=$ Child number of word types (free play) } \\
\hline Predictors & $\beta$ & $t$ & Step $F$ & Step $R^{2}$ \\
\hline 1. Mother number of utterances (free play) & 0.27 & 1.33 & $F(1,24)=4.07 \dagger$ & 0.15 \\
\hline \multirow[t]{2}{*}{ 2. Mother Control function (free play) } & -0.29 & -1.43 & $F(1,23)=2.03$ & 0.07 \\
\hline & \multicolumn{4}{|c|}{$D P=$ Child number of word types (mealtime) } \\
\hline Predictors & $\beta$ & $t$ & Step $F$ & Step $R^{2}$ \\
\hline 1. Mother number of utterances (mealtime) & 0.17 & 0.94 & $F(1,24)=3.85 \dagger$ & 0.14 \\
\hline \multirow[t]{2}{*}{ 2. Mother Tutorial function (mealtime) } & $0.53^{\star \star}$ & $2.99^{\star \star}$ & $F(1,23)=8.96^{\star \star}$ & 0.24 \\
\hline & \multicolumn{4}{|c|}{$D P=$ Child number of word types (mealtime) } \\
\hline Predictors & $\beta$ & $t$ & Step F & Step $R^{2}$ \\
\hline 1. Mother number of utterances (mealtime) & 0.33 & 1.76 & $F(1,24)=3.85 t$ & 0.14 \\
\hline \multirow[t]{2}{*}{ 2. Mother Didactic function (mealtime) } & 0.29 & 1.55 & $F(1,23)=2.42$ & 0.08 \\
\hline & \multicolumn{4}{|c|}{$D P=$ Child number of word types (mealtime) } \\
\hline Predictors & $\beta$ & $t$ & Step $F$ & Step $R^{2}$ \\
\hline 1. Mother number of utterances (mealtime) & 0.28 & 1.64 & $F(1,24)=3.85 \dagger$ & 0.14 \\
\hline 2. Mother Control function (mealtime) & -0.46 & $-2.65^{\star \star}$ & $F(1,23)=7.03^{\star \star}$ & 0.20 \\
\hline
\end{tabular}

Note. $\uparrow: 0.05<p<0.10 ;{ }^{\star}: p \leqslant 0.05 ;{ }^{\star \star}: p \leqslant 0.01 ; \mathrm{DP}:$ dependent variable.

did not exhibit significant contextual stability; in addition, the production of attuned mind-related comments was more frequent in the free-play than in the mealtime context. As explained later, these findings suggest that mind-mindedness should be better regarded as a relational construct and in this respect contradict previous evidence suggesting strong temporal and relational stability (Kirk et al., 2015; Illingworth et al., 2016). Along the same line, our results contribute new, unprecedented evidence showing that different communicative functions exhibit different degrees of stability and continuity. As illustrated by Bornstein et al. (2017), group mean-level continuity and individual-order stability can coexist in complex ways, such that a given characteristic can exhibit continuity and stability, continuity and instability, discontinuity and stability, or discontinuity and instability. Communicative functions showed several of these combinations, with the Tutorial function being both stable and continuous, the Control function being stable but discontinuous, and the Conversational function being both unstable and discontinuous. Finally, the analysis of the concurrent relations between mothers and children's measures contributed to extend the results reported by Longobardi et al. (2018) to a different time point (16 months rather than 20 months), a different context (mealtime rather than free-play) and a different measurement method 
Table 6. Hierarchical regressions predicting children's number of word tokens from maternal measures

\begin{tabular}{|c|c|c|c|c|}
\hline \multirow[b]{2}{*}{ Predictors } & \multicolumn{4}{|c|}{$D P=$ Child number of word tokens (free play) } \\
\hline & $\beta$ & $t$ & Step $F$ & Step $R^{2}$ \\
\hline 1. Mother number of utterances (free play) & 0.21 & 1.09 & $F(1,24)=2.49$ & 0.09 \\
\hline \multirow[t]{2}{*}{ 2. Mother Tutorial function (free play) } & $0.38 \dagger$ & $1.97 \dagger$ & $F(1,23)=3.88 \dagger$ & 0.13 \\
\hline & \multicolumn{4}{|c|}{$D P=$ Child number of word tokens (mealtime) } \\
\hline Predictors & $\beta$ & $t$ & Step $F$ & Step $R^{2}$ \\
\hline 1. Mother number of utterances (free play) & 0.21 & 0.99 & $F(1,24)=2.49$ & 0.09 \\
\hline \multirow[t]{2}{*}{ 2. Mother Control function (free play) } & -0.25 & -1.18 & $F(1,23)=1.41$ & 0.05 \\
\hline & \multicolumn{4}{|c|}{$D P=$ Child number of word tokens (mealtime) } \\
\hline Predictors & $\beta$ & $t$ & Step $F$ & Step $R^{2}$ \\
\hline 1. Mother number of utterances (mealtime) & 0.28 & 1.53 & $F(1,24)=5.69^{\star}$ & 0.19 \\
\hline \multirow[t]{2}{*}{ 2. Mother Tutorial function (mealtime) } & 0.40 & $2.17^{\star}$ & $F(1,23)=4.72^{\star}$ & 0.14 \\
\hline & \multicolumn{4}{|c|}{$D P=$ Child number of word tokens (mealtime) } \\
\hline Predictors & $\beta$ & $t$ & Step F & Step $R^{2}$ \\
\hline 1. Mother number of utterances (mealtime) & 0.37 & $2.24^{\star}$ & $F(1,24)=5.69^{\star}$ & 0.19 \\
\hline \multirow[t]{2}{*}{ 2. Mother Didactic function (mealtime) } & 0.45 & $2.71^{\star \star}$ & $F(1,23)=7.38^{\star \star}$ & 0.20 \\
\hline & \multicolumn{4}{|c|}{$D P=$ Child number of word tokens (mealtime) } \\
\hline Predictors & $\beta$ & $t$ & Step $F$ & Step $R^{2}$ \\
\hline 1. Mother number of utterances (mealtime) & 0.36 & $2.10^{\star}$ & $F(1,24)=5.69^{\star}$ & 0.19 \\
\hline 2. Mother Control function (mealtime) & -0.41 & $-2.41^{\star}$ & $F(1,23)=5.84^{\star}$ & 0.16 \\
\hline
\end{tabular}

Note. †: $0.05<p<0.10 ;{ }^{*}: p \leqslant 0.05 ;{ }^{\star *}: p \leqslant 0.01 ; \mathrm{DP}$ : dependent variable.

(observational measures rather than parent-report measures). Briefly, we found that children's language was positively associated with the number of words produced by mothers and with their use of the Tutorial and Didactic functions, but negatively associated with their use of the Control function. With respect to maternal mind-mindedness, the proportions of attuned and non-attuned comments were unrelated to the number of words produced by children in both contexts, thus contradicting previous reports by Laranjo and Bernier (2013) and Bernier et al. (2017) and further supporting the idea that communicative functions and mind-mindedness play different roles in the prediction of children's language. In the following paragraphs, we will discuss in more details the implications of this set of findings for the comprehension of the roles of maternal mind-mindedness and communicative functions in the development of children's language.

\section{Mind-mindedness}

Regarding contextual continuity, our results, showing greater proportions of attuned mind-related comments in free-play than in mealtime, are in contrast with those reported by Helmerhorst et al. (2019), who instead found no contextual differences. 
The discrepancy might be related to the fact that Helmerhorst and colleagues measured the mind-mindedness of childcare assistants, whereas our investigation focused on maternal mind-mindedness. Different caregivers may be expected to interact with children in different ways, although the overall proportion of attuned mind-related comments reported by Helmerhorst et al. (2019) was very similar to that computed in the present study (9.90 vs. 10.36, averaged across free-play and mealtime contexts). Furthermore, the childcare assistants examined by Helmerhorst et al. (2019) interacted with infant, preschool and mixed-age groups ranging from 0 to 4 years, whereas our interactions were always recorded at 16 months.

Regardless of the possible explanation, the current results support the idea that differences in the interactional context may influence the quality of the interactions between children and their caregivers. Previous studies indicate that routine contexts, such as mealtime, are primarily directed towards the satisfaction of children's needs and are therefore less likely to involve complex interactions; in contrast, play situations are well suited to stimulate more sophisticated exchanges in which mothers must take the children's perspective and try to interpret the desires, the beliefs and the emotions underlying their behaviors (Degotardi, 2010; Hoff-Ginsberg, 1991; Yont, Snow \& Vernon-Feagans, 2003). Flynn and Masur (2007), for example, examined the frequency with which mothers used four mutually exclusive categories of responsive and directive speech during bath and play sessions at 10, 13, 17 and 21 months. The results showed that mothers produced both responsive utterances (i.e., descriptions of actions or objects that followed the child's focus of attention) and supportive directives (i.e., utterances aimed at suggesting, commanding or encouraging that followed the child's focus of attention) more frequently in the play than in the bath context. Our findings extend these conclusions by demonstrating that different contexts can modulate the mothers' ability and willingness to perceive their children as psychological agents with their own repertoires of internal states. In agreement, Farkas et al. (2018) found that mothers used more mental state references during storytelling than during free play. Since we did not examine mind-mindedness during storytelling, an interesting avenue for future research would be to compare the production of attuned mind-related comments across multiple contexts (e.g., routine, free play and storytelling contexts).

For contextual stability, our findings converge with those found by Helmerhorst et al. (2019) in showing that maternal mind-mindedness did not exhibit significant contextual stability. This result speaks to the question of whether mind-mindedness can be described as a cognitive-behavioral trait (as originally suggested, among the others, by Meins et al., 2011) or as a relational construct. The characterization of mind-mindedness as a cognitive-behavioral trait implies consistency in mothers' responses across different relationships and contexts, whereas the characterization as a relational construct implies that maternal mind-mindedness should be highly variable and governed by the specific relation or context investigated (Illingworth et al., 2016). As briefly reviewed in the Introduction, previous studies investigating interactional mind-mindedness have reported mixed findings: significant stability over time and consistency across different relationships have been reported, among the others, by Meins et al. (2011), Kirk et al. (2015) and Illingworth et al. (2016); however, other studies found little evidence of temporal or contextual stability (Giovanelli et al., 2019; Helmerhorst et al., 2019).

From this perspective, the present results might suggest that maternal mind-mindedness can be better characterized as a relational construct, because the 
correlation between the production of attuned mind-related comments in the free play and mealtime contexts was small in size and non-significant. According to Bornstein et al. (2020), the finding of small or null stability can reflect many different factors. One factor which is obviously involved in our study is whether assessments are made across consistent or inconsistent contexts. The idea is that consistent contexts enhance stability, whereas inconsistent contexts tend to reduce stability (Bornstein et al., 2020). As noted above, the goal-directed agenda of routine contexts (such as mealtime or bathing) is clearly different from the more interactive agenda of free play contexts (Degotardi, 2010; Flynn \& Masur, 2007; Helmerhorst et al., 2019). The specific characteristics of the mealtime context might provide mothers with fewer opportunities to express their mind-mindedness skills. If this was the case, then the stability coefficients computed in the present study should be considered as lower bound estimates. Future studies might want to compare different contextual situations, in which mothers are supposed to have similar opportunities to interpret the behaviors of their infants and to comment on putative internal states-for example, free-play vs. storytelling (Farkas et al., 2018; Hoff, 2010). We expect that the contextual stability of maternal mind-mindedness should increase in these conditions. Another potentially relevant factor is the age of children in the period in which maternal measures were assessed (Bornstein et al., 2020). All our dyads were examined when children were approximately 16 months old. The second year of life is known to be a period of dramatic social, cognitive and linguistic growth in which mothers are continuously required to modify the properties of the input directed to their children. We cannot exclude that contextual stability might have been higher had we examined maternal speech during the first year of life (Meins et al., 2011) or after the second birthday (Illingworth et al., 2016).

As for the concurrent relations between maternal and child measures, we found that the proportions of attuned and non-attuned mind-related comments produced by mothers were not associated with the number of words produced by children in the free-play and mealtime contexts. This is not, however, the first study to report non-significant concurrent correlations: Meins et al. (2013), for example, found that maternal attuned comments at 26 months were not related to children's internal and non-internal state vocabulary; on a related note, Farkas et al. (2018) showed that mothers' mental state references did not predict concurrent children's language, neither at Time 1 (when children were between 10 and 15 months old) nor at Time 2 (when children were between 28 and 33 months old). At least two different factors might account for the present results. First, most previous studies reporting significant associations between maternal mind-mindedness and children's vocabulary have used longitudinal (rather than cross-sectional) designs and have assessed infant language via indirect parent-report questionnaires, such as the McArthur Communicative Development Inventory (Bernier et al., 2017; Laranjo \& Bernier, 2013; Meins et al., 2013). These positive relations might be partly driven by the fact that mothers with high levels of mind-mindedness are more willing to detect novel words pronounced by their children, or even to interpret words from their infants' babbling, and report them in parent reports (Meins, 1998). Second, maternal mind-mindedness might have a positive impact on specific aspects of children's language that were not assessed in the present study. In this respect, Longobardi et al. (2018) found that the proportions of attuned mind-related comments produced by mothers at 16 months predicted children's internal state language at 20 months but were unrelated to their non-internal state language. Similarly, Meins et al. (2013) 
proposed that the positive effects of maternal mind-mindedness might be more evident on receptive verbal tasks that explicitly require perspective taking, rather than on expressive tasks requiring straightforward object labeling.

\section{Communicative functions}

In the present study, significant contextual differences were observed in three out of five communicative functions. Specifically, the use of the Control function was more frequent during play than during mealtime, suggesting that the increased complexity of the free-play condition and the higher levels of children's involvement prompted mothers to increase their reliance upon action and attention directives. This is well in line with the results reported in the study by Masur and Turner (2001), in which directiveness was also higher in the play than in the bath session. Interestingly, we also found that mothers produced significantly more asynchronous and non-attuned mind-related comments in the play context than in the mealtime. Although the extremely low frequencies of these categories (especially in the routine session) suggest caution in interpreting these data, it appears that mothers had much more difficulty in following their child's focus of attention/action during play activities. In agreement, in the study by Flynn and Masur (2007), intrusive attentional directives were produced $50 \%$ more frequently during play than during bath. Future studies should confirm this conclusion by examining conditions that are likely to increase the production of asynchronous and non-attuned comments. This might require, for example, the involvement of adolescent mothers (Demers, Bernier, Tarabulsy \& Provost, 2010) or mothers at risk for depression (Bigelow et al., 2018).

Two other points concerning the contextual continuity of maternal speech should be discussed. First, unlike the Control and Asynchronous functions, the Conversational function was used more frequently during mealtime than during play. This suggests that, in the mealtime context, children were less willing to verbally interact with their mothers, who were therefore induced to produce more utterances aimed at promoting and maintaining the communicative exchange. This interpretation is supported by the finding that children's verbosity was significant lower in the mealtime than in the play session. Second, the analysis of general language measures indicated that mothers used more words and utterances during the play context; however, their overall MLU was greater in the mealtime context. The latter result can be understood by considering that Control comments (which were produced more frequently in the play context) took often the form of imperative sentences (e.g., 'prendi il giocattolo': 'take the toy') and, as a consequence, tended to be shorter than Conversational comments (which were produced more frequently in the mealtime context).

Turning to discuss the stability issues, our correlational findings indicate that the asynchronous function was highly stable, whereas the tutorial and control functions were only moderately stable ${ }^{1}$. Moreover, in the follow-up regressions, only the asynchronous function showed significant contextual stability after controlling for children's language. No stability was observed for the Didactic and Conversational functions. On the one hand, the stability of the asynchronous function supports the conclusions previously reached by Flynn and Masur (2007), who showed that

\footnotetext{
${ }^{1}$ The widely-accepted Cohen's (1988) rule of thumb is to interpret $r=0.10$ as a small effect size, $r=0.30$ as a medium effect size, $r=0.50$ as a large effect size, and $r=0.70$ as a very large effect size (Bornstein et al., 2020).
} 
intrusive attentional directives were considerably consistent across the play and bath contexts. On the other hand, the mixed results concerning the tutorial and didactic functions are somewhat in contrast with the high consistency of responsive utterances observed by these authors (Flynn \& Masur, 2007; see also Masur \& Turner, 2001). As discussed in relation to mind-mindedness, the relatively low consistency of communicative functions in the present study might be accounted for by differences in mothers' behavioral goals in the free-play and mealtime contexts (Helmerhorst et al., 2019) or by the specific age of our children.

Lastly, the analysis of the concurrent relations between maternal communicative functions and children's language replicated previous evidence showing that, especially in the mealtime context, mothers who used the tutorial and didactic functions more frequently had children who produced more word types and tokens, whereas the mothers who used the control function more frequently had children who produced fewer word types and tokens (Longobardi, 1992, 1995; Longobardi et al., 2018; Majorano et al., 2013) ${ }^{2}$. The general consensus is that maternal reformulations, expansions, references to a shared experience, descriptions and corrections (i.e., the most relevant categories involved in the Tutorial and Didactic functions) facilitate the matching of novel words to concrete references by providing children with labels for objects, actions and subjective mental states under episodes of joint attention (Callanan, Akhtar \& Sussman, 2014; Tamis-LeMonda et al., 2001). On the other hand, an extensive usage of the Control function may be detrimental to early language acquisition because lexical diversity in maternal directive utterances is comparatively lower than that in responsive utterances, a factor which is known to hinder infants' vocabulary growth (Song, Spier \& Tamis-LeMonda, 2014).

\section{Limitations and conclusions}

The present study has several limitations that must be discussed. A first element to consider is that our sample was limited in size. Studies assessing direct measures of mothers' and children's language in a variety of contexts or at different time points are notoriously demanding in terms of time, and similar sample sizes have been often reported in previous research (Flynn \& Masur, 2007; Kirk et al., 2015; Illingworth et al., 2016; Masur \& Turner, 2001). Furthermore, the finding that mothers' general language measures exhibited robust contextual stability in our study suggests that the small-to-moderate correlations observed for mind-mindedness and communicative function measures cannot be entirely ascribed to problems of statistical power. Nevertheless, our conclusions concerning the contextual stability of maternal speech needs to be replicated in larger samples. A second limitation is that mother-child dyads were only examined at 16 months. As suggest by Bornstein et al. (2020), a given characteristic may not be stable at one age, but stabilize at later ages; furthermore, mothers and their children are expected to become increasingly stable in relation to one another as they age. It is therefore essential to ascertain whether our conclusions can be extended to different ages. Finally, we assessed mind-

\footnotetext{
${ }^{2}$ Note that the frequency of use of the Tutorial function was negatively correlated with the frequency of use of the Control function $(r=-0.54, p=0.004$ in the free-play context and $r=-0.56, p=0.003$ in the mealtime context); in addition, the frequency of use of the Didactic function was negatively correlated with the frequency of use of the Control function in the mealtime context $(r=-0.49, p=0.010)$, but not in the free-play context $(r=-0.11, p=0.61)$.
} 
mindedness and communicative functions in two contexts that are different in terms of goals and types of interactions (Flynn \& Masur, 2007; Helmerhorst et al., 2019; Hoff, 2006). Analyzing the same measures in two similar contexts might yield higher stability estimates: as noted above, the book reading context is a good candidate because it bears many similarities with the free-play context (Farkas et al., 2018).

Even with these limitations in mind, our study is one of the few to examine the continuity and stability of multiple measures of maternal responsiveness in two typical and naturally occurring interactive contexts and to relate them to children's language. The significant contextual differences and the low-to-moderate stability coefficients evidenced by our results highlight the importance of taking into account the variability introduced by different communicative contexts in children's language acquisition (Flynn \& Masur, 2007; Hoff, 2006). They also suggest that more data are needed to determine whether mind-mindedness and communicative functions can be considered as stable cognitive-behavioral traits or as dimensions of a relational construct linked to contextual, child and parental characteristics (Illingworth et al., 2016; McMahon \& Bernier, 2017).

\section{References}

Bernier, A., McMahon, C. A., \& Perrier, R. (2017). Maternal mind-mindedness and children's school readiness: A longitudinal study of developmental processes. Developmental Psychology, 53(2), 210221. doi: $10.1037 / \mathrm{dev} 0000225$

Bigelow, A. E., Beebe, B., Power, M., Stafford, A.-L., Ewing, J., Egleson, A., \& Kaminer, T. (2018). Longitudinal relations among maternal depressive symptoms, maternal mind-mindedness, and infant attachment behavior. Infant Behavior \& Development, 51, 33-44. doi: 10.1016/j.infbeh.2018.02.006

Bornstein, M. H., Hahn, C.-S., \& Haynes, O. M. (2004). Specific and general language performance across early childhood: Stability and gender considerations. First Language, 24(72,Pt3), 267-304. doi: 10.1177/ 0142723704045681

Bornstein, M. H., Putnick, D. L., \& Esposito, G. (2017). Continuity and stability in development. Child Development Perspectives, 11(2), 113-119. doi: 10.1111/cdep.12221

Bornstein, M. H., Putnick, D. L., Hahn, C. S., Tamis-LeMonda, C. S., \& Esposito, G. (2020). Stabilities of infant behaviors and maternal responses to them. Infancy, 25(3), 226-245.

Bornstein, M. H., \& Tamis-LeMonda, C. S. (1997). Maternal responsiveness and infant mental abilities: Specific predictive relations. Infant Behavior \& Development, 20(3), 283-296. doi:10.1016/S0163-6383 (97)90001-1

Bornstein, M. H., Tamis-LeMonda, C. S., \& Haynes, O. M. (1999). First words in the second year: Continuity, stability, and models of concurrent and predictive correspondence in vocabulary and verbal responsiveness across age and context. Infant Behavior \& Development, 22(1), 65-85. doi: 10.1016/S0163-6383(99)80006-X

Bornstein, M. H., Tamis-LeMonda, C. S., Tal, J., Ludemann, P., Toda, S., Rahn, C. W., Pecheux, M.-G., Azuma, H., \& Vardi, D. (1992). Maternal responsiveness to infants in three societies: The United States, France, and Japan. Child Development, 63(4), 808-821. doi: 10.2307/1131235

Callanan, M. A., Akhtar, N., \& Sussman, L. (2014). Learning words from labeling and directive speech. First Language, 34(5), 450-461. doi: 10.1177/0142723714553517

Camaioni, L., \& Longobardi, E. (2001). Noun versus verb emphasis in Italian mother-to-child speech. Journal of Child Language, 28, 773-785.

Camaioni, L., Longobardi, E., Venuti, P., \& Bornstein, M. H. (1998). Maternal speech to 1-year-old children in two Italian cultural contexts. Early Development \& Parenting, 7(1), 9-18. doi: 10.1002/ (SICI) 1099-0917(199803)7:1<9::AID-EDP159>3.0.CO;2-T

Centifanti, L. C. M., Meins, E., \& Fernyhough, C. (2016). Callous-unemotional traits and impulsivity: Distinct longitudinal relations with mind-mindedness and understanding of others. Journal of Child Psychology and Psychiatry, 57(1), 84-92. doi:10.1111/jcpp.12445. 
Cohen, J. (1988). Statistical Power Analysis for the Behavioral Sciences, 2nd ed. Hillsdale, NJ: Psychology Press.

D'Odorico, L., Salerni, N., Cassibba, R., \& Jacob, V. (1999). Stability and change of maternal speech to Italian infants from 7 to 21 months of age: A longitudinal study of its influence on early stages of language acquisition. First Language, 19(57), 313-346. doi: 10.1177/014272379901905702

De Winter, S., Waters, T. E. A., Braet, C., \& Bosmans, G. (2018). Middle childhood problem behaviors: Testing the transaction between responsive parenting, temperament, and attachment-related processing biases. Journal of Child and Family Studies, 27(3), 916-927. doi: 10.1007/s10826-017-0924-0

Degotardi, S. (2010). High-quality interactions with infants: Relationships with early-childhood practitioners' interpretations and qualification levels in play and routine contexts. International Journal of Early Years Education, 18(1), 27-41. doi: 10.1080/09669761003661253

Demers, I., Bernier, A., Tarabulsy, G. M., \& Provost, M. A. (2010). Mind-mindedness in adult and adolescent mothers: Relations to maternal sensitivity and infant attachment. International Journal of Behavioral Development, 34(6), 529-537. doi:10.1177/0165025410365802

Doan, S. N., Fuller-Rowell, T. E., \& Evans, G. W. (2012). Cumulative risk and adolescent's internalizing and externalizing problems: The mediating roles of maternal responsiveness and self-regulation. Developmental Psychology, 48(6), 1529-1539. doi: 10.1037/a0027815

Farkas, C., del Real, M. T., Strasser, K., Álvarez, C., Santelices, M. P., \& Sieverson, C. (2018). Maternal mental state language during storytelling versus free-play contexts and its relation to child language and socioemotional outcomes at 12 and 30 months of age. Cognitive Development, 47, 181-197. doi: 10.1016/ j.cogdev.2018.06.009

Flynn, V., \& Masur, E. F. (2007). Characteristics of maternal verbal style: Responsiveness and directiveness in two natural contexts. Journal of Child Language, 34(3), 519-543. doi: 10.1017/S030500090700801X

George, D., \& Mallery, M. (2010). SPSS for Windows Step by Step: A Simple Guide and Reference, 17.0 update (10a ed.). Boston: Pearson.

Giovanelli, C., Di Dio, C., Lombardi, E., Tagini, A., Meins, E., Marchetti, A., \& Carli, L. (2019). Exploring the relation between maternal mind-mindedness and children's symbolic play: A longitudinal study from 6 to 18 months. Infancy. doi: 10.1111/infa.12317

Helmerhorst, K. O. W., Colonnesi, C., \& Fukkink, R. G. (2019). Caregiver's mind-mindedness in early center-based childcare. Early Education and Development, 30(7), 854-871. https://doi-org.ezproxy. uniroma1.it/10.1080/10409289.2019.1593076

Hoff, E. (2006). How social contexts support and shape language development. Developmental Review, 26 (1), 55-88. doi: 10.1016/j.dr.2005.11.002

Hoff, E. (2010). Context effects on young children's language use: The influence of conversational setting and partner. First Language, 30(3-4), 461-472. doi: 10.1177/0142723710370525

Hoff-Ginsberg, E. (1991). Mother-child conversation in different social classes and communicative settings. Child Development, 62(4), 782-796. doi: 10.2307/1131177

Iverson, J. M., Longobardi, E., \& Caselli, M. C. (2003). Relationship between gestures and words in children with Down's syndrome and typically developing children in the early stages of communicative development. International Journal of Language \& Communication Disorders, 38(2), 179-197. doi: 10.1080/1368282031000062891

Illingworth, G., MacLean, M., \& Wiggs, L. (2016). Maternal mind-mindedness: Stability over time and consistency across relationships. European Journal of Developmental Psychology, 13(4), 488-503. doi: 10.1080/17405629.2015.1115342

Kirk, E., Pine, K., Wheatley, L., Howlett, N., Schulz, J., \& Fletcher, B. (C). (2015). A longitudinal investigation of the relationship between maternal mind-mindedness and theory of mind. British Journal of Developmental Psychology, 33(4), 434-445. doi:10.1111/bjdp.12104

Landry, S. H., Smith, K. E., \& Swank, P. R. (2006). Responsive parenting: Establishing early foundations for social, communication, and independent problem-solving skills. Developmental Psychology, 42(4), 627-642. doi: 10.1037/0012-1649.42.4.627.supp

Laranjo, J., Bernier, A., \& Meins, E. (2008). Associations between maternal mind-mindedness and infant attachment security: Investigating the mediating role of maternal sensitivity. Infant Behavior of Development, 31(4), 688-695. doi: 10.1016/j.infbeh.2008.04.008 
Laranjo, J., Bernier, A., Meins, E., \& Carlson, S. M. (2014). The roles of maternal mind-mindedness and infant security of attachment in predicting preschoolers' understanding of visual perspective taking and false belief. Journal of Experimental Child Psychology, 125, 48-62. doi: 10.1016/j.jecp.2014.02.005

Laranjo, J., \& Bernier, A. (2013). Children's expressive language in early toddlerhood: Links to prior maternal mind-mindedness. Early Child Development and Care, 183(7), 951-962. doi: 10.1080/ 03004430.2012 .699964

Longobardi, E. (1992). Funzione comunicativa del comportamento materno e sviluppo comunicativo-linguistico del bambino nel secondo anno di vita [Communicative functions of maternal behavior and the communicative-linguistic development of children in the second year of life]. Giornale Italiano Di Psicologia, 19(3), 425-448.

Longobardi, E. (1995). Funzioni comunicative materne nel secondo anno di vita del bambino: come varia il supporto materno in relazione allo sviluppo linguistico. Rassegna di psicologia, XII, 67-83.

Longobardi, E., Rienzi, S., Spataro, P., \& Colonnesi, C. (2015a). Funzioni comunicative e mind-mindedness nell'interazione madre-bambino a 16 mesi di età [Communicative functions and mind-mindedness in mother-child interactions at 16 months of age]. Psicologia Clinica Dello Sviluppo, 19(2), 345-355.

Longobardi, E., Rossi-Arnaud, C., Spataro, P., Putnick, D. L., \& Bornstein, M. H. (2015b). Children's acquisition of nouns and verbs in Italian: Contrasting the roles of frequency and positional salience in maternal language. Journal of Child Language, 42(1), 95-121. doi: 10.1017/S0305000913000597

Longobardi, E., Spataro, P., \& Colonnesi, C. (2018). Maternal communicative functions and mind-mindedness at 16 months as predictors of children's internal and non-internal language at 20 months. Infant Behavior \& Development, 50, 52-63. doi: 10.1016/j.infbeh.2017.11.003

Longobardi, E., Spataro, P., Putnick, D. L., \& Bornstein, M. H. (2016). Noun and verb production in maternal and child language: Continuity, stability, and prediction across the second year of life. Language Learning and Development, 12(2), 183-198. doi: 10.1080/15475441.2015.1048339

Lucassen, N., Tharner, A., Van IJzendoorn, M. H., Bakermans-Kranenburg, M. J., Volling, B. L., Verhulst, F. C., Lambregtse-Van den Berg, M. P., \& Tiemeier, H. (2011). The association between paternal sensitivity and infant-father attachment security: A meta-analysis of three decades of research. Journal of Family Psychology, 25(6), 986-992. doi: 10.1037/a0025855

Lundy, B. L. (2013). Paternal and maternal mind-mindedness and preschoolers' theory of mind: The mediating role of interactional attunement. Social Development, 22(1), 58-74. doi: 10.1111/sode.12009

McDonald, L., \& Pien, D. (1982). Mother conversational behaviour as a function of interactional intent. Journal of Child Language, 9(2), 337-358. doi: 10.1017/S030500090000475X

McMahon, C. A., \& Bernier, A. (2017). Twenty years of research on parental mind-mindedness: Empirical findings, theoretical and methodological challenges, and new directions. Developmental Review, 46, 54-80. doi: 10.1016/j.dr.2017.07.001

Mcquaid, N., Bigelow, A. E., McLaughlin, J., \& MacLean, K. (2008). Maternal mental state language and preschool children's attachment security: Relation to children's mental state language and expressions of emotional understanding. Social Development, 17(1), 61-83. doi: 10.1111/j.1467-9507.2007.00415.x

Majorano, M., Rainieri, C., \& Corsano, P. (2013). Parents' child-directed communication and child language development: A longitudinal study with Italian toddlers. Journal of Child Language, 40(4), 836-859. doi: $10.1017 /$ S0305000912000323

Masur, E. F., Flynn, V., \& Eichorst, D. L. (2005). Maternal responsive and directive behaviours and utterances as predictors of children's lexical development. Journal of Child Language, 32(1), 63-91. doi: $10.1017 /$ S0305000904006634

Masur, E. F., \& Turner, M. (2001). Stability and consistency in mothers' and infants' interactive styles. Merrill-Palmer Quarterly, 47(1), 100-120. doi: 10.1353/mpq.2001.0003

Meins, E. (1998). The effects of security of attachment and maternal attribution of meaning on children's linguistic acquisitional style. Infant Behavior \& Development, 21(2), 237-252. doi: 10.1016/S0163-6383 (98)90004-2

Meins, E., \& Fernyhough, C. (1999). Linguistic acquisitional style and mentalising development: The role of maternal mind-mindedness. Cognitive Development, 14(3), 363-380. doi: 10.1016/S0885-2014(99) 00010-6

Meins, E., \& Fernyhough, C. (2015). Mind-mindedness coding manual, Version 2.2 Unpublished manuscript. University of York, York, UK. 
Meins, E., Fernyhough, C., Arnott, B., Leekam, S. R., \& Rosnay, M. (2013). Mind-mindedness and theory of mind: Mediating roles of language and perspectival symbolic play. Child Development, 84 (5), 1777-1790. doi: 10.1111/cdev.12061

Meins, E., Fernyhough, C., Arnott, B., Turner, M., \& Leekam, S. R. (2011). Mother-versus infantcentered correlates of maternal mind-mindedness in the first year of life. Infancy, 16(2), 137-165.

Meins, E., Fernyhough, C., de Rosnay, M., Arnott, B., Leekam, S. R., \& Turner, M. (2012). Mind-mindedness as a multidimensional construct: Appropriate and nonattuned mind-related comments independently predict infant-mother attachment in a socially diverse sample. Infancy, 17 (4), 393-415. doi: 10.1111/j.1532-7078.2011.00087.x

Meins, E., Fernyhough, C., Fradley, E., \& Tuckey, M. (2001). Rethinking maternal sensitivity: Mothers' comments on infants' mental processes predict security of attachment at 12 months. Journal of Child Psychology and Psychiatry, 42(5), 637-648. doi: 10.1111/1469-7610.00759

Meins, E., Fernyhough, C., Russell, J., \& Clark-Carter, D. (1998). Security of attachment as a predictor of symbolic and mentalising abilities: A longitudinal study. Social Development, 7(1), 1-24. doi: 10.1111/ 1467-9507.00047

Meins, E., Fernyhough, C., Wainwright, R., Clark-Carter, D., Gupta, M. D., Fradley, E., \& Tuckey, M. (2003). Pathways to Understanding Mind: Construct Validity and Predictive Validity of Maternal Mind-Mindedness. Child Development, 74(4), 1194-1211. doi: 10.1111/1467-8624.00601

Miller, J. E., Kim, S., Boldt, L. J., Goffin, K. C., \& Kochanska, G. (2019). Long-term sequelae of mothers' and fathers' mind-mindedness in infancy: A developmental path to children's attachment at age 10. Developmental Psychology, 55(4), 675-686. doi: 10.1037/dev0000660

Paavola-Ruotsalainen, L., Lehtosaari, J., Palomäki, J., \& Tervo, I. (2018). Maternal verbal responsiveness and directiveness: Consistency, stability, and relations to child early linguistic development. Journal of Child Language, 45(2), 319-339. doi: 10.1017/S030500091700023X

Pan, B. A., Imbens-Bailey, A., Winner, K., \& Snow, C. (1996). Communicative intents expressed by parents in interaction with young children. Merrill-Palmer Quarterly, 42(2), 248-266.

Song, L., Spier, E. T., \& Tamis-LeMonda, C. S. (2014). Reciprocal influences between maternal language and children's language and cognitive development in low-income families. Journal of Child Language, 41(2), 305-326. doi: 10.1017/S0305000912000700

Tamis-LeMonda, C. S., Bornstein, M. H., \& Baumwell, L. (2001). Maternal responsiveness and children's achievement of language milestones. Child Development, 72(3), 748-767. doi: 10.1111/1467-8624.00313

Tamis-LeMonda, C. S., Kuchirko, Y., \& Song, L. (2014). Why is infant language learning facilitated by parental responsiveness? Current Directions in Psychological Science, 23(2), 121-126. doi: 10.1177/ 0963721414522813

Thal, D. J., \& Tobias, S. (1992). Communicative gestures in children with delayed onset of oral expressive vocabulary. Journal of Speech \& Hearing Research, 35(6), 1281-1289. doi: 10.1044/jshr.3506.1289

Wade, M., Jenkins, J. M., Venkadasalam, V. P., Binnoon-Erez, N., \& Ganea, P. A. (2018). The role of maternal responsiveness and linguistic input in pre-academic skill development: A longitudinal analysis of pathways. Cognitive Development, 45, 125-140. doi: 10.1016/j.cogdev.2018.01.005

Yont, K. M., Snow, C. E., \& Vernon-Feagans, L. (2003). The role of context in mother-child interactions: An analysis of communicative intents expressed during toy play and book reading with 12-month-olds. Journal of Pragmatics, 35(3), 435-454. doi: 10.1016/S0378-2166(02)00144-3

Zeegers, M. A. J., Colonnesi, C., Stams, G.-J. J. M., \& Meins, E. (2017). Mind matters: A meta-analysis on parental mentalization and sensitivity as predictors of infant-parent attachment. Psychological Bulletin, 143(12), 1245-1272. doi: 10.1037/bul0000114.supp

Cite this article: Longobardi E, Spataro P, Calabrò M (2022). Maternal mind-mindedness and communicative functions in free-play and mealtime contexts: Stability, continuity and relations with child language at 16 months. Journal of Child Language 49, 635-660. https://doi.org/10.1017/ S0305000920000835 